Volume 10, No.6, November - December 2021

International Journal of Advanced Trends in Computer Science and Engineering

Available Online at http://www.warse.org/IJATCSE/static/pdf/file/ijatcse011062021.pdf

https://doi.org/10.30534/ijatcse/2021/011062021

\title{
User Engagement and User Design on Online Shopping Apps
}

\author{
John Albert Balansag ${ }^{1}$, Rommel A. Canoy ${ }^{2}$, Troyd B. Puquiz ${ }^{3}$, Honey Marjey V. Curay ${ }^{4}$, Denver F. Divino ${ }^{5}$, \\ Luz Clarisse E. Pejera ${ }^{6}$, Mark Van M. Buladaco* ${ }^{* 7}$ \\ ${ }^{123456}$ Student, Bachelor of Science in Information Technology, Davao del Norte State College, Philippines \\ ${ }^{7}$ Dean, Institute of Computing, Davao del Norte State College \\ *markvan.buladaco@dnsc.edu.ph
}

Received Date : October 05, 2021 Accepted Date : November 01, 2021 Published Date : December 06, 2021

\begin{abstract}
Most people nowadays use mobile phones, and they do a lot of things with this device, including online shopping through an app since it saves a lot of time, and they can choose a broad range of products even with just a small screen. User engagement is one of the factors that affect the design of an app. Referring to the quality of the user that emphasizes the interaction between the user and the app. Numerous studies internationally have studied user engagement and app design but not specifically with the user engagement towards shopping apps design. We conducted this study to assess the effectiveness of user engagement towards online shopping apps design. Also, the purpose of this study is to identify user engagement factors that will produce a successful good shopping app design. The results show a high level of user engagement and online shopping apps design. It has also been found that among the indicators of user engagement, attention and satisfaction are the two predictors of the design of online shopping apps.
\end{abstract}

Key words: Correlational Research, User Engagement, Online Shopping Apps Design, Davao Region

\section{INTRODUCTION}

\subsection{Background of the Study}

Today almost everyone has a mobile phone at hand. According to Samarhan, mobile phones have become an integral part of people's lives, and no one can further imagine the daily routines without having a mobile device at pocket. Mobile phones can do more than just listening. They can do shopping, make payments, texting, videos, photos, and do many other things [1]. And following this revolution of internet usage, users' behavior has changed the way they purchase goods and services, stated by Hussain, Mkpojiogu, and Suleiman [2]. Once individuals attain the status of experienced e-shoppers, their behavior becomes similar [3]. As we all know, people nowadays shop online, especially on their mobile devices. And according to Liu, Z.C. and Lu, Z.W, in the consumer buying process, the environment is one of the great factors that affect purchase intention and behavior. Thus, the market gives great importance to the app design of the shop environment to have a higher chance of final purchase [4]. Many factors hinder the user engagement of the shopping app. One of those is that the customer cannot examine the object physically before purchasing. Thus, shopping apps are designed to provide many pictures and consumer reviews from other customers [5]. It means that the shopping app engages the customer with the app and gives the other customers ideas. This study will highlight the importance of user engagement with a shopping app and how this makes good design and features give a rich experience.

A good app makes sense or is desired if the goal is to have an interactive engagement with users or provide an application that requires work more akin to a computer program than a website [6]. Based on Liu, Z.C. and Lu, Z.W, it needs to change the large and all-inclusive idea from the original PC side website design in the app design aspect. It must display the core and important information in a limited page space with an important standard of convenience. The design should allow consumers to quickly see the information they need most and avoid consumer visual fatigue in the process of browsing and should consider both genders for the visual interface in the app design [4], [7]. Also, there are bad apps, which means it's not conforming to standards. An app can be considered to be bad if it has a poor design/UI, has poor navigation, does not meet the user requirements, and has security issues. Apps must be updated regularly to keep customers focused and engaged [6]. As users are becoming more and more accustomed to high-quality elements in apps, it is important to meet the same standards in enterprise application design. This involves understanding how motivation and emotion may affect users' perception of experience resulting from design features that promote interest, aesthetics, and etc.[8], [9].

To understand how user engagement is essential to apps design, it is necessary to understand user engagement and which key attributes make up engagement. The definition of "engage," according to Random House Dictionary, is "to occupy the attention or efforts of,""to attract, hold fast or please," and "become involved." These general keywords are applied in numerous subjects but overall represent what engagement stands for [10]-[12]. User engagement can be essential to a mobile application's success. Users' behavior has an impact on the churn rate. Also, it presents implications on 
the company's intent of growing a user base, since a single user can influence several other users to try an app, which is an important factor for the growth of the company. Not only does it matter in terms of getting visibility and growing a user base, but it is also essential from a business perspective, since users' actions online; like clicking, commenting, and sharing have an impact on important behaviors to the application, such as purchasing or donating [11]. As it stands, an increase in user engagement can result in a rise in revenues and app growth [13].

We observed that there are no regional/national context studies related to this topic. In the international context, only a little research conducted a relationship between user engagement and apps design. This study sought to address that problem by identifying and measuring the effectiveness of user engagement factors that successfully produce a good app design specifically in shopping/e-commerce and will conform to the standards. In this case, we will look into how user engagement fosters the app's success and what people's attention and action in the real world when using shopping apps.

\subsection{Theoretical Framework}

The theory used in this research is the IS Success Model. It was developed by William H. DeLone and Ephraim R. McLean in 1992 and later updated in 2003, and it was used in many studies. The study that helped us discover this theory is Product Customization on the Web: An Empirical Study of Factors Impacting Choiceboard User Satisfaction. The IS Success Model indicates that it offers six interrelated constructs of information systems success measures. That describes the quality dimensions which could affect succeeding user satisfaction. It also indicates that some benefits designated as net benefits will be achieved as a result of use with user satisfaction. These net benefits could consequently affect user satisfaction and continued use of the system [14].

These are the six critical dimensions of IS Success Model System quality: Measures the desirable characteristics of an information system. This has been measured by many IS studies using such characteristics as being flexible, response time, and easy to use [15]. Information quality: It involves content issues and characteristics of the information systems output. It has been measured by examining the information system output regarding timeliness, correctness, reliability, and integrity[15]. Service quality is measured in terms of the quality of support by the information system's developer. Studies have assessed this using service quality dimensions, which are responsiveness and assurance by the systems support department and the provision of user training[15]. Intentions to Use/Use: This involves in assessing how an information system is used. Various studies have measured this by examining actual usage or, sometimes, the frequency of use [15]. User satisfaction: This construct is one of the most important measures of systems success, often measured by overall user satisfaction [15], [16]. Net benefits:
Considered one of the most significant measures of IS success, it designates the extent to which an IS contributes to the success of many stakeholders, whether it is positive or negative. It has been measured by sometimes assessing the individual impact or organizational impact[15].

As applied to our study, this theory holds that we would expect our independent variable(s) user engagement to influence or explain the dependent variable(s) online shopping apps design because this study is trying to prove that higher user engagement means that the online shopping apps design is good. And the IS Success model theory has six critical dimensions: system quality, information quality, service quality, intention to use, user satisfaction, and net benefits. As we can see, these constructs and measures that are explained above can be applied to our variables. Thus, it will help us to assess user engagement and shopping apps design.

\subsection{Conceptual Framework}

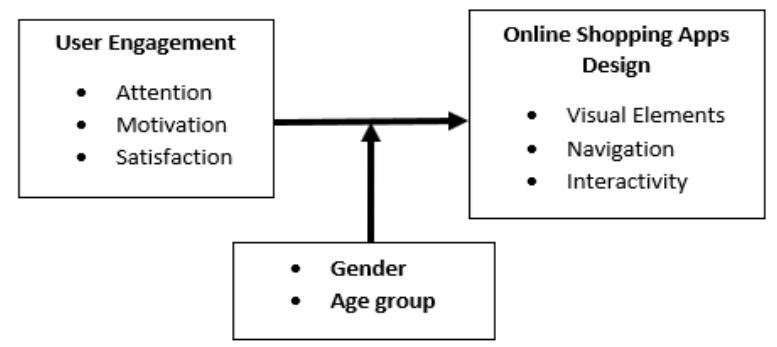

Figure 1: Conceptual Framework

The figure above shows the conceptual framework model that will be used in this study. At the left side box represents the independent variable, and at the right side is the dependent variable and both boxes contain their respective indicators. Lastly, the lower box contains the moderating variables that will affect the relationship between independent and dependent variables.

\subsection{Research Questions}

RQ1. What is the demographic profile of the participants of the study in terms of:

a. Gender

b. Age group

RQ2. What is the level of user engagement in terms of:

a. Attention

b. Motivation

c. Satisfaction

RQ3. What is the level of online shopping apps design in terms of:

a. Visual Elements

b. Navigation

c. Interactivity

RQ4. Is there a significant difference in the level of user engagement when grouped according to:

a. Age group

b. Gender 
RQ5. Is there a significant difference in the level of online shopping apps design when grouped according to:
a. Age group

b. Gender

RQ6. Is there a significant relationship between the level of user engagement and the level of online shopping apps design?

RQ7. Do user engagement significantly influence the online shopping apps design?

\subsection{Null Hypothesis}

Ho1: There is no significant difference in the level of user engagement when grouped according to:

a. Age Group

b. Gender

Ho2: There is no significant difference in the level of online shopping apps design when grouped according to:

a. Age Group

b. Gender

Ho3: There is no significant relationship between the level of user engagement and in the level of online shopping apps design.

Ho4: The user engagement does not significantly influence the online shopping apps design.

\section{METHODOLOGY}

\subsection{Research Design}

The researchers in this study used correlational research as a design. Correlational research is a non-experimental quantitative research method that measures two variables and understands and assesses their statistical relationship. This research method is suited for this study because it involves a comparison of the data gathered, which can help evaluate and determine the relationship between user engagement and online shopping apps design.

\subsection{Research Locale}

The study was conducted at Davao del Norte State College, a public college in New Visayas, Panabo City, Philippines. The questionnaires were distributed on an online platform, and the respondents were different citizens from Davao Region.

\subsection{Participants of the Study}

The study respondents were citizens from any province or city of the Davao Region who had used shopping apps when buying items online. The respondents were selected by using quota sampling, and the questionnaires were distributed to the target respondents. The inclusion criteria are those males/females 13 years old and above who have used shopping apps on their smartphones.

\subsection{Sampling Techniques}

In this study, the researchers used non-probability sampling which is quota sampling. This non-probability sampling technique selects samples based on subjective judgment rather than random selection [17]. The researchers used this sampling technique because they targeted 200 respondents and it has a moderating variable of age group and gender.

\subsection{Statistical Treatments}

All the data gathered from the online survey questionnaires were tallied and tabulated using statistical software. The researchers asked for assistance from the statistician to analyze and interpret the results utilizing the appropriate statistical tool.

Mean - Also known as arithmetic average, the mean is the average or the most common value in a data set [18].

Standard Deviation - is a statistic measurement for the dispersion of a dataset relative to its mean and is calculated as the square root of the variance [19].

T-test - An inferential statistic used to estimate the significant difference between the means of two groups using the ratio of the difference in group means over the pooled standard error of both groups [20].

ANOVA - A statistical test that compares the means between the groups and determines whether any of those means are statistically significantly different from each other [21].

Pearson's $R$ - also known as Pearson correlation coefficient measures the strength of the association between the two variables and has a value between +1 and -1 [22].

Linear Regression is used to show or predict the relationship between two variables or factors [23].

\subsection{Data Collection Procedure}

The researcher crafted a letter of consent to the target respondents to provide sufficient information about the study. The letter of consent had been given to the participants via Facebook messenger/Google forms, and the participants read out those forms that they were willing to participate. The researcher also used Facebook messenger and google forms for gathering data. The data had been collected and tabulated with the help of a statistician. The results became the basis of the Effectiveness of User Engagement towards Online Shopping Apps Design

\subsection{Research Instrument}

The research instrument used is an online questionnaire that consists of 3 parts. Part I of the questionnaire gathered the demographic profile, which are the participants' name, age, and gender. Part II and Part III of the questionnaire consists of a series of questions. Specifically, user engagement for part II, online shopping apps design for part III. The questionnaires were based on multiple researches. These are "Mobile User Engagement: New Apps versus Mainstream Apps"[11], "Consumer's Attitude towards Online Shopping"[24], and "User Interface Design of Mobile-based Commerce"[25].

\subsection{Ethical Considerations}

Ethical issues had been considered during the procedure of this study. Ethical considerations during the research include: 
Informed Consent. The researchers released consent to the target participants to ask for permission and the consent indicates the purpose and procedures of the study.

Confidentiality. Researchers ensured that the respondent's identity does not be revealed in any way in the report as a means to protect their privacy [26].

Potential for harm. This study avoids all unnecessary physical and mental suffering [27].

Plagiarism. Researchers had been careful about using the material from others and properly cited the reference [28] .

Misrepresentation of results. The researchers didn't falsify the results of the study [29].

\section{RESULTS AND DISCUSSIONS}

The gathered data has been carefully analyzed in this study. The following information are the results of the collected data from the survey.

Table 1. Demographic Profile

\begin{tabular}{|c|c|c|c|}
\hline $\begin{array}{c}\text { Characteristic } \\
(\mathbf{n = 2 0 0})\end{array}$ & Level & No. & \% \\
\hline Gender & Male & 113 & 56.5 \\
\hline & Female & 87 & 43.5 \\
\hline Age Group & $13-17$ & 56 & 28.0 \\
\hline & $18-24$ & 91 & 45.5 \\
\hline & $25-34$ & 37 & 18.5 \\
\hline & Above 34 & 16 & 8.0 \\
\hline
\end{tabular}

Table 1 shows the demographic profile of the respondents and their respective percent and numbers according to level. With the total of 200 participants, consisting $56.5 \%$ male and $43.5 \%$ female in gender. For the age group 28\% were 13-17 years old, $45.5 \%$ were $18-24$ years old, $18.5 \%$ were $25-34$ years old, and $8 \%$ were $34+$ years old.

Table 2. Level of User Engagement

\begin{tabular}{|c|c|c|c|}
\hline Indicators & Mean & SD & Description \\
\hline Attention & 3.7750 & .70059 & High \\
\hline Motivation & 3.8060 & .76871 & High \\
\hline Satisfaction & 3.6720 & .76613 & High \\
\hline Overall & $\mathbf{3 . 7 5 1 0}$ & $\mathbf{. 6 7 4 7 7}$ & High \\
\hline
\end{tabular}

Table 2 shows the level of user engagement in terms of its indicators. Particularly the mean, standard Deviation, and description. The mean of the level of attention of the respondents is 3.7750 with a standard deviation of 0.70059 . This shows that the attention of the respondents is high. The mean of the level of motivation of the respondents is 3.8060 with a standard deviation of 0.76871 . This shows that the motivation of the respondents is high. The mean of the level of satisfaction of the respondents is 3.6720 with a standard deviation of 0.76613 . This shows that the satisfaction of the respondents is high. The mean of the level of the user engagement is 3.7510 with a standard deviation of 0.67477 . This shows that the level of the user engagement is high when using an online shopping app.

The results implies respondents have high engagement when using online shopping apps. Interest and involvement to enter the application's environment are one of the major drivers of engagement, as engaged users are frequently found to be effectively involved with the app's success [11].

Table 3. Level of Online Shopping Apps Design

\begin{tabular}{|c|c|c|c|}
\hline Indicators & Mean & SD & Description \\
\hline $\begin{array}{c}\text { Visual } \\
\text { Elements }\end{array}$ & 4.1490 & .73587 & High \\
\hline Navigation & 3.8920 & .79264 & High \\
\hline Interactivity & 3.8440 & .80380 & High \\
\hline Overall & $\mathbf{3 . 9 6 1 7}$ & $\mathbf{. 7 2 2 7 2}$ & High \\
\hline
\end{tabular}

Table 3 shows the level of online shopping apps design in terms of its indicators. Particularly the mean, standard Deviation, and description. The mean of the level of visual elements to all users is 4.1490 with a standard deviation of 0.73587 . This shows that the level of visual elements to all users is high. The mean of the level of navigation is 3.8920 with a standard deviation of 0.79264 . This shows that the level of navigation is high. The mean of the level of interactivity is 3.8440 with a standard deviation of 0.80380 . This shows that the level of interactivity is high. The mean of the level of online shopping apps design use is 43.9617 with a standard deviation of 0.72272 . This shows that the level of online shopping apps design use is high.

This result implies that the design is crucial for the online shopping app. It allows the users to avoid frustration, and the app needs to conform to the standards and meets the user requirements [6].

Table 4. Significant Difference in the Level of User Engagement when Respondents are Grouped According to Age Group and Gender ANOVA (Between Groups)

\begin{tabular}{|c|c|c|c|c|c|}
\hline & $\begin{array}{c}\text { Sum of } \\
\text { squares }\end{array}$ & df & $\begin{array}{c}\text { Mean } \\
\text { Square }\end{array}$ & $\mathbf{F}$ & Sig. \\
\hline $\begin{array}{c}\text { UEMean } \\
\text { (Age } \\
\text { Group) }\end{array}$ & 1.286 & 3 & .429 & .940 & .422 \\
\hline $\begin{array}{c}\text { UEMean } \\
\text { (Gender) }\end{array}$ & 1.301 & 1 & 1.301 & 2.884 & .091 \\
\hline
\end{tabular}


Table 4 shows the significant difference in the level of user engagement when grouped according to age group and gender. Since the p-value when grouped to age group is $0.422>0.05$, then we do not reject the null hypothesis. There is no significant difference in the user engagement when grouped according to age group. Since the p-value is $0.091>0.05$ when grouped to gender, then we do not reject the null hypothesis. There is no significant difference in the user engagement when grouped according to gender.

When a user experiences e-shopping despite their age, their behavior with other users are similar [3]. In purchasing online, males and females may have different preferences when purchasing a product, but they have the same motivation factor in the buying process: consumer reviews [5].

Table 5. Significant Difference in the Level of Online Shopping Apps Design when Respondents are Grouped According to Age Group and Gender ANOVA (Between Groups)

\begin{tabular}{|c|c|c|c|c|c|}
\hline & $\begin{array}{c}\text { Sum of } \\
\text { squares }\end{array}$ & df & $\begin{array}{c}\text { Mean } \\
\text { Square }\end{array}$ & F & Sig. \\
\hline $\begin{array}{c}\text { OSAD } \\
\text { Mean } \\
\text { (Age Group) }\end{array}$ & 4.038 & 3 & 1.346 & 2.640 & .051 \\
\hline $\begin{array}{c}\text { OSAD } \\
\text { Mean(Gender) }\end{array}$ & 1.281 & 1 & 1.281 & 2.471 & .118 \\
\hline
\end{tabular}

Table 5 shows the significant difference in the online shopping apps design level when grouped according to age group and gender. Since the p-value of the age group is $0.051>0.05$, we do not reject the null hypothesis. There is no significant difference in online shopping apps design when grouped according to age group. Since the p-value of gender is $0.118>0.05$, we do not reject the null hypothesis. There is no significant difference in the online shopping apps design when grouped according to gender.

This implies that with the considerations for all ages, designing a shopping app should be easy on the eyes to avoid visual fatigue in the process of browsing [4]. The interface design for the shopping apps should not focus on a single gender, but need to consider both gender[7].

Table 6. Correlations of Significant Relationship between the User Engagement and Online Shopping Apps Design

\begin{tabular}{|c|c|c|c|}
\hline & & UEMean & $\begin{array}{c}\text { OSAD } \\
\text { Mean }\end{array}$ \\
\hline UEMean & $\begin{array}{c}\text { Pearson } \\
\text { Correlation }\end{array}$ & 1 & $.737^{* *}$ \\
\hline & Sig. (2-tailed) & & .000 \\
\hline OSAD & $\mathrm{N}$ & 200 & 200 \\
\hline
\end{tabular}

\begin{tabular}{|c|c|c|c|}
\hline Mean & Correlation & & \\
\hline & Sig. (2-tailed) & .000 & \\
\hline & $\mathrm{N}$ & 200 & 200 \\
\hline
\end{tabular}

**. Correlation is significant at the 0.01 level (2-tailed).

The $\mathrm{r}$-value is 0.737 which means that there is a strong positive relationship in the user engagement to the online shopping apps design. Since p-value is $0.000<0.05$, then we reject the null hypothesis. There is a significant relationship in the user engagement to the online shopping apps design.This implies that user engagement aims to excite and attract the user. This involves understanding how motivation and emotion may affect users' perception of experience resulting from design features that promote interest and aesthetics of the app design [9].

\section{Effectiveness of User Engagement towards Online Shopping Apps Design}

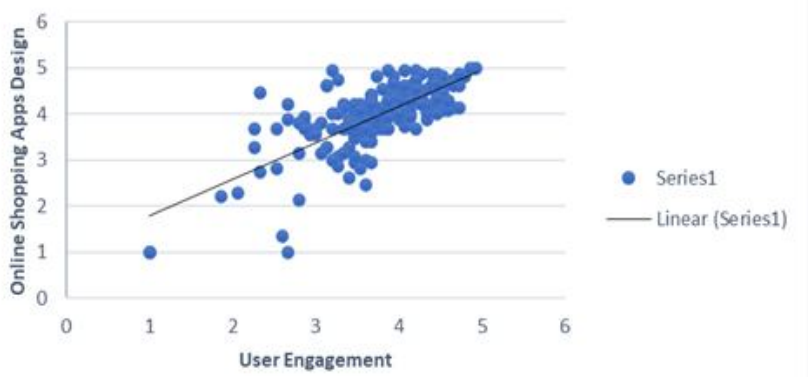

Fig. 2 Scatterplot of data values

The blue dots represent the 200 coordinates that stand as each respondent's scores in the independent and dependent variables. The black line stands for the trend of relationship that represents the arrangement of the dots.

Table 7. Model Summary

\begin{tabular}{|l|l|l|l|l|}
\hline Model & $\mathbf{R}$ & $\begin{array}{c}\mathbf{R} \\
\text { Square }\end{array}$ & $\begin{array}{c}\text { Adjusted } \\
\text { R Square }\end{array}$ & $\begin{array}{c}\text { Std. Error } \\
\text { of the } \\
\text { Estimate }\end{array}$ \\
\hline 1 & $.760^{\mathrm{a}}$ & .577 & .571 & .47348 \\
\hline
\end{tabular}

a. Predictors: (Constant), AttentionMean, MotivationMean, SatisfactionMean

Table 8. Coefficients

\begin{tabular}{|l|l|l|l|l|l|l|}
\hline & & \multicolumn{2}{|l|}{$\begin{array}{l}\text { Unstandardiz } \\
\text { ed } \\
\text { Coefficients }\end{array}$} & $\begin{array}{c}\text { Stan } \\
\text { dard } \\
\text { ized } \\
\text { Coe } \\
\text { ffici } \\
\text { ents }\end{array}$ & & \\
& & & & & \\
\hline Mo & & B & Std. & Beta & t & Sig \\
\hline
\end{tabular}




\begin{tabular}{|l|c|l|l|l|l|l|}
\hline del & & & Error & & & \\
\hline 1 & (Constant) & $\mathbf{1 . 0 5 0}$ & .192 & & 5.455 & .000 \\
\hline & $\begin{array}{c}\text { A } \\
\text { Mean }\end{array}$ &. $\mathbf{1 7 2}$ & .075 & .167 & 2.305 & $\mathbf{. 0 2 2}$ \\
\hline $\begin{array}{c}\text { M } \\
\text { Mean }\end{array}$ & $\mathbf{. 0 8 0}$ & .076 & .085 & 1.054 & .293 \\
\hline $\begin{array}{c}\text { S } \\
\text { Mean }\end{array}$ & $\mathbf{. 5 3 3}$ & .070 & .565 & 7.629 & $\mathbf{. 0 0 0}$ \\
\hline
\end{tabular}

a. Dependent Variable: OSADMean

Using stepwise regression, it has found out that among the indicators of the user engagement, attention and satisfaction are the two predictors of the online shopping apps design. The prediction is illustrated by the equation $\mathrm{y}=$ $0.172 \mathrm{x}_{1}+0.533 \mathrm{x}_{3}+1.050$, with a predictive power of $57.70 \%$.

This means that in order to have a good shopping apps design the users should have engaging activities with the app. Satisfaction as one of the predictors makes the online shopping apps design successful, Delone and McLean IS success model user satisfaction indicates that it directly influences the net benefits [16]. This means that a good satisfied experience of users leads to a growing user base of the shopping app [11]. Also, grabbing and holding the user's attention means that the user is having an engaging experience with an online shopping app [12].

\section{CONCLUSIONS AND RECOMMENDATIONS}

This chapter presents the conclusions and recommendations derived in the conduct of the study which is to identify and measure the effectiveness of user engagement towards the online shopping apps design.

\subsection{Conclusions}

The conclusions of the findings for the effectiveness of user engagement towards online shopping apps design were based among the respondents which are shopping app users in Davao Region. The conclusions are as follows:

1. The demographic profile of the participants of this study are 200 shopping app users in Davao Region, specifically 113 males and 87 females. For the age groups $(13-17=56$ respondents), $(18-24=91$ respondents $), \quad(25-34=37$ respondents), and (above $34=16$ respondents).

2 . The results show that the level of user engagement is high in terms of attention, motivation, and satisfaction. This means that the users are highly engaged when using a shopping app.

3 . The results show that the level of online shopping apps design is high in terms of visual elements, navigation, and interactivity. This means that these functional designs are key factors when designing shopping apps.

4. The results show that there is no significant difference in user engagement when grouped according to age group and gender. This means that users who attain the status of experienced e-shoppers become similar to other users, regardless of their age and gender.

5. The results show that there is no significant difference in the level of online shopping apps design when grouped according to age group and gender. This means that the shopping apps design should be for all ages, and the design elements should be gender-neutral.

6. The results show that there is a strong positive relationship in the level of user engagement towards the online shopping apps design. This means that the perception and emotions of the user when engaging with the shopping app resulting in features that promote good shopping app design.

7. It has been found out that among the indicators of user engagement, attention and satisfaction are the two predictors of online shopping apps design. The user's satisfaction and attention were the predictor factors that successfully produce a good app design. The user's attention was captured on good visual interface, color scheme, high-quality images, gamification, and responsive navigation in the shopping app. And with this, satisfaction occurs, which leads to a higher purchase intention and a growing number of customers.

\subsection{Recommendations}

This study revealed the effectiveness of user engagement towards online shopping apps design. Thus, the following recommendations are at this moment presented: since the effectiveness of user engagement has been proven, developers should take considerations in the engagement activities when designing a shopping app. The visual elements and interactivity should be consistent in navigating the shopping app. Lastly, for the future researchers, a further study may be conducted to continue, improve and develop user engagement towards shopping apps design.

\section{ACKNOWLEDGEMENTS}

We would like to express our deep and sincere gratitude to our adviser Mr. Mark Van Buladaco MIT, Professor and Dean of Institute of Computing for his endless support, patience and encouragement. His guidance helped us a lot in the time of research and writing this paper.

We would like to thank Mr. Ellvan Campos for being our statistician who produces results and analysis to make this study possible.

We would like to thank the Institute of Computing, classmates, friends,and our families for their undying support to us. We are also extremely grateful to the people who supported us to complete this research paper directly or indirectly. Lastly, to all research group members, this study will not be possible without your support and contributions.

\section{REFERENCES}

[1] A. Samarhan, "In-Store Consumer Shopping Behaviour Through Mobile Phones," p. 69.

[2] "A Heuristic Evaluation of Achik.biz Mobile Shopping App," Int. J. Recent Technol. Eng., vol. 8, no. 2S2, pp. 123-126, Jul. 2019, doi: 10.35940/ijrte.B1023.0782S219. 
[3] B. Hernandez, J. Jimenez, and M. J. Martın, "really moderate online shopping behaviour?,"" p. 22.

[4] Z. Liu and Z. Lu, ""Research on Influence of Shopping APP's Characteristic on Consumer's Impulse Buying," Mod. Econ., vol. 08, no. 12, pp. 1484-1498, 2017, doi: 10.4236/me.2017.812099.

[5] L. P. Ling, "Does Gender Play A Role In Online Consumer Behavior?," p. 9.

[6] V. N Inukollu, D. D. Keshamon, T. Kang, and M. Inukollu, "Factors Influncing Quality of Mobile Apps: Role of Mobile App Development Life Cycle," Int. J. Softw. Eng. Appl., vol. 5, no. 5, pp. 15-34, Sep. 2014, doi: 10.5121/ijsea.2014.5502.

[7] A. Baharum, E. A. Rahim, R. Hanapi, N. A. Mat Noor, and N. M. MohdYusop, "Evaluating gender-based mobile shopping application using eye-tracking technology," Indones. J. Electr. Eng. Comput. Sci., vol. 13, no. 3, p. 1095, Mar. 2019, doi: 10.11591/ijeecs.v13.i3.pp10951101.

[8] R. Newhook, D. Jaramillo, J. G. Temple, and K. J. Duke, "Evolution of the Mobile Enterprise App: A Design Perspective," Procedia Manuf., vol. 3, pp. 2026-2033, 2015, doi: 10.1016/j.promfg.2015.07.250.

[9] A. Sutcliffe, "Designing for User Experience and Engagement," 2016, pp. 105-126.

[10] Dictionary.com, "Engage | Definition of Engage at Dictionary.com."

https://www.dictionary.com/browse/engage?s=t (accessed Dec. 17, 2020).

[11] M. Leiras, "Mobile User Engagement: New Apps versus Mainstream Apps," p. 43.

[12] H. L. O'Brien and E. G. Toms, "What is user engagement? A conceptual framework for defining user engagement with technology," J. Am. Soc. Inf. Sci. Technol., vol. 59, no. 6, pp. 938-955, Apr. 2008, doi: 10.1002/asi.20801.

[13] D. Permadi and A. Rafi, "DEVELOPING A CONCEPTUAL MODEL OF USER ENGAGEMENT FOR MOBILE-BASED AUGMENTED REALITY GAMES," J. Teknol., vol. 77, no. 29, Dec. 2015, doi: 10.11113/jt.v77.6804.

[14] A. I. Ojo, "Validation of the DeLone and McLean Information Systems Success Model," Healthc. Inform. Res., vol. 23, no. 1, pp. 60-66, Jan. 2017, doi: 10.4258/hir.2017.23.1.60.

[15] S. Petter, W. DeLone, and E. McLean, "Measuring information systems success: models, dimensions, measures, and interrelationships," Eur. J. Inf. Syst., vol. 17, no. 3, pp. 236-263, Jun. 2008, doi: 10.1057/ejis.2008.15.

[16] W. H. Delone and E. R. Mclean, "The DeLone and McLean Model of Information Systems Success: A TenYear Update," p. 22.

[17] QuestionPro, "Non-Probability Sampling: Definition, types, Examples, and advantages," QuestionPro, Apr. 30, 2018. https://www.questionpro.com/blog/non-probabilitysampling/ (accessed Dec. 27, 2020).

[18] Khan Academy, "Statistics intro: Mean, median, \& mode (video)," Khan Academy. https://www.khanacademy.org/math/cc-sixth-grade- math/cc-6th-data-statistics/mean-and-median/v/statisticsintro-mean-median-and-mode (accessed Dec. 27, 2020).

[19] LaerdStatistics, "Standard Deviation | How and when to use the Sample and Population Standard Deviation - A measure of spread | Laerd Statistics." https://statistics.laerd.com/statistical-guides/measures-ofspread-standard-deviation.php (accessed Dec. 27, 2020).

[20] Scribbr, "An Introduction to T-Tests | Definitions, Formula and Examples," Scribbr, Jan. 31, 2020. https://www.scribbr.com/statistics/t-test/ (accessed Dec. 27, 2020).

[21] LaerdStatistics, "One-way ANOVA - An introduction to when you should run this test and the test hypothesis | Laerd Statistics." https://statistics.laerd.com/statisticalguides/one-way-anova-statistical-guide.php (accessed Dec. 27, 2020).

[22] Faculty of Health and Applied Sciences, "Data Analysis Pearson's Correlation Coefficient." http://learntech.uwe.ac.uk/da/default.aspx?pageid=1442 (accessed Dec. 27, 2020).

[23] The Balance Small Business, A. E. M. R. in C. Satisfaction, and business proposals R. T. B. editorial policies G. DeVault, "How Simple Linear Regression, Used to Analyze Quantitative Data," The Balance Small Business. https://www.thebalancesmb.com/what-issimple-linear-regression-2296697 (accessed Dec. 27, 2020).

[24] M. U. Sultan and M. N. Uddin, Consumers' Attitude towards Online Shopping: Factors influencing Gotland consumers to shop online. 2011.

[25] O. A. Supriadi, "User Interface Design of Mobile-based Commerce," IOP Conf. Ser. Mater. Sci. Eng., vol. 662, p. 022047, Nov. 2019, doi: 10.1088/1757899X/662/2/022047.

[26] T. E. S. C. 2700 E. P. N. Olympia, W. 98505867-6000 Phone, and E. Directories, "Understanding Confidentiality and Anonymity | The Evergreen State College."

https://www.evergreen.edu/humansubjectsreview/confide ntiality (accessed Dec. 28, 2020).

[27] Business Research Methodology (BRM), "Ethical Considerations - Research Methodology," ResearchMethodology. https://research-methodology.net/researchmethodology/ethical-considerations/ (accessed Dec. 28, 2020).

[28] Plagramme, "Ethics Of Plagiarism - Plagramme.com plagiarism checker," Ethics Of Plagiarism Plagramme.com plagiarism checker. https://www.plagramme.com/ethics-of-plagiarism (accessed Dec. 28, 2020).

[29] PennState, "2.1 Falsification, Fabrication, Plagiarism | BIOET 533: Ethical Dimensions of Renewable Energy and Sustainability Systems." https://www.eeducation.psu.edu/bioet533/node/654 (accessed Dec. 28, 2020). 